Jurnal Keperawatan Padjadjaran

ISSN 2338-5324 (print)

ISSN 2442-7276 (online)

Online di http://jkp.fkep.unpad.ac.id

DOI : $10.24198 / \mathrm{jkp}$

\title{
Beta Binaural Beats and its effects on the Cognition of Nursing Students in a Private Higher Education Institution
}

\author{
Julie Ann C. Dy ${ }^{1}$, April Ross S. Ladera ${ }^{1}$, Joshua Paul J. Cabato ${ }^{1}$, Monique O. Librando ${ }^{1}$, Johnny \\ J. Yao Jr' \\ ${ }^{1}$ College of Nursing, Velez College, Philippines \\ ${ }^{2}$ College of Nursing, Cebu Normal University, Philippines \\ Corresponding email: johnnyyaojr@gmail.com
}

Submitted: 17-05-2020 Accepted: 29-06-2020 Published: 01-08-2020

\begin{abstract}
Studying nursing comes with a certain expectation to work hard and take a certain amount of time. A promising method called beta binaural beats is thought to improve cognitive functions. This study aimed to determine whether listening to beta beats is an effective method for improving cognition among nursing students. A doubleblinded experimental research design was utilized and measured the effects of the intervention towards memory, abstract reasoning and reading comprehension. A total of 89 subjects participated in this study. Only the score of reading comprehension showed a significant difference $(t=2.38, p=.02)$. The findings suggest that beta beats is an effective way in enhancing reading comprehension. However, findings show that beats aren't effective in enhancing memory and abstract reasoning. Therefore, this may be used as a method to enhance learning.
\end{abstract}

Keywords: Abstract reasoning, beta binaural beats, cognition, memory, nursing students, reading comprehension. 
Johnny J. Yao Jr: Beta Binaural Beats and Its Effect on The Cognition of Nursing Students

\section{Introduction}

A student carries a lot of responsibilities and one of the essential key responsibilities is to study. Many students enter college expecting good times, friendship and a good sense of direction. However, that is not always the case, students later figure out how challenging and struggling college life is. A study by Dy et al. (2015) entitled "Stressors and Stress Responses of Filipino College Students" stated that out of 258 students, $72 \%$ manifested cognitive stress responses due to academic stressors.

Moreover, studying nursing comes with a certain expectation to work harder on average than most other students. They deal with lectures and practical taking up a great deal of time. In addition, nursing is considered to be one of the most stressful career choices. It entails student to gain knowledge and skill through classroom lectures, long exam, return demonstration and rotating shift works in the hospital and participate in community programs.

A nurse is required to know anatomy and physiology, biology, pharmacology and other areas of nursing science. However, nursing students have difficulty in remembering too much information. A study conducted by Potter et al. (2005) stated that nurses who have lower working memory capacity are more likely to make medical errors.

Furthermore, usually most students read and highlight terms or definitions they don't even understand (Conca, 2010). Although remembering concepts are significant, it is highly important to be able to comprehend as well since nurses play a huge role in providing patient education. Contextualized learning experience and collaborative construction of knowledge is important in achieving positive outcomes for students' clinical- reasoning skills (Yauri et al., 2019).

As early as their first year, nursing students are taught to think outside the box. They are trained to develop critical thinking skills. Nurses are faced with decision-making situations in patient care, and each decision they make impacts patient outcomes. Nursing critical thinking skills drive the decisionmaking process and impact the quality of care provided (Vest as cited in Ericksen, 2017).
As students in the chosen profession for the present study, the researchers have witnessed the need for improving cognitive processes: memory, reading comprehension and abstract reasoning. Students often complain on how to attain memory retention while being able to comprehend medical terms and as to how to choose the best answer in situational questions during long exams.

Based on literature, there is a promising tool used to enhance cognitive functions called binaural beats. Binaural beats, discovered by Heinrich Wilhelm Dove, is the difference between two pure tones with different frequencies introduced to each ear separately that is perceived by the brain (Oster, 1973). It has shown to entrain brainwaves from one state to another. Binaural beats is thought to exert effect on cognitive functioning and mood (Lane et al., 1998) specifically beta binaural beats. A study conducted by GarciaArgibay et al. (2017) revealed significant findings of beta frequency binaural beats amounting to 20 hertz to the subjects who performed free recall and recognition tasks. Exposure to beta frequency binaural beats yielded a great proportion of correctly recalled words and a higher index in recognition tasks. Another study on the effects of beta binaural beats conducted on college students showed a significant increase in their memory (Kennerly, 2013). This study test investigated whether listening to beta binaural beats is an effective method for improving cognition such as memory, reading comprehension and abstract reasoning among nursing students.

\section{Methods}

An experimental research design was utilized in the study wherein an intervention or treatment was introduced. Experimental studies are designed to test causal relationships to test whether the intervention caused changes in or affected the dependent variable (Polit \& Beck, 2017). The dependent variables are the quality of memory, reading comprehension, abstract reasoning and the independent variable is the use of binaural beats.

The study was performed in an institution in highly urbanized city in the Philippines 
offering five programs of study: Nursing, Medical Technology, Physical and Occupational Therapy and Biology. The subjects were from the fourth-year nursing students. Experiment was done in one of the classrooms for two days. The room can accommodate up to 50 people and is air conditioned and well ventilated.

The researchers decided to utilize the total population of the fourth-year nursing students, which is a total of 100 subjects excluding the researchers. They are divided into two sections. Section A has 52 students while Section B has 48 students. Only 89 subjects participated (45 for experimental group, 44 for control group) in the study since eight of these students had another important school activity to attend to, two of the students had an important family event and one was excluded from the study due to a heart problem (premature ventricular contractions). Majority (83\%) of the subjects were females (See Table 1). The study was approved by Velez College Ethics Review Committee prior to data collection. All eligible research subjects were informed through phone or personal contact that they were invited to participate in the study and should meet the researchers at the actual research venue for a short orientation. Eligible students were asked to read the consent form which contained the procedure, duration and sessions, possible risks and benefits of the study involved in the binaural beats music therapy. The subjects were randomly assigned to either experimental or control group. The subjects were screened first with a researcher made screening tool which required them to write their names and age. A yes or no question screening tool was given since there were certain conditions which were contraindicated with binaural beats such as seizure, individuals with pacemakers and heart problems and to know if the subjects had their own earphones and smartphones. The researchers lent smartphones and earphones for those who didn't have. The participants were blinded and did not know which group they were assigned. The study only took one session for each subject since the immediate psychological effects on memory, attention were shown to benefit from even a single session of brainwave entrainment (Huang \&
Charyton, 2008). Brainwave Entrainment is a method of influencing or shifting brainwave patterns and binaural beats is type of audio brainwave entrainment. The binaural beats were done in the same room but in a different day for each section. To enhance attendance in the study the students were reminded personally or was contacted through their phone to remind them about the scheduled session. Each subject was required to bring their own earphones and phone to be used during the intervention. There were 2 audio files, one file contains the beta binaural beats (experimental) and the other has the delta binaural beats (control), one of the 2 files were blue toothed randomly by the researchers to each subject's smartphone. A pretest was given first followed by the intervention. During the intervention everyone followed the signal of the researchers as to when they would play and listen to the binaural beats. They were informed that they are not allowed to listen to any other music but only the binaural beats. The control group listened to delta binaural beats while the experimental group listened to beta binaural beats for 15 minutes. The beta binaural beats used is standardized already in which the difference between two ears is $20 \mathrm{~Hz}$ since we are using beta beats it should be around 14-30 hertz and the volume was on what the subject is most comfortable with. Once everyone was done listening to the binaural beats, they immediately took the post test. The pretest and post test questions were not of the same content but had the same level of difficulty.

To test for memory, a researcher made tool was given in which 20 random medical-related words were mentioned for a maximum of five minutes and then the research subjects were asked to write as much as they can remember after they took the reading comprehension exam. For reading comprehension the International English Language Testing System will be the instrument used. It is the most appropriate instrument to measure the variable. The IELTS is an international standardized test of English language proficiency. IELTS has four parts which are the following: listening, reading, writing which are completed in one sitting and speaking. Only the reading part of the IELTS was utilized by the researchers. It 
is composed of 13 items in which they have to answer questions regarding the story or article they have read. For abstract reasoning, the Non-Verbal Figurative Test by GetMyUni (n.d.) was used. It is composed of 15 items in which they were to choose from the choices on which figure was missing. The scores were interpreted by getting the mean score for each test and then standard deviation was used to measure how scores differ from the mean score.

Statistical analysis was done using SPSS with $p<0.05$ as the significant value. Demographic data were processed using descriptive statistical analysis. In addition, the differences between and within groups were analyzed using the paired t-test, and independent t-test

\section{Results}

A total of 89 subjects participated in this study. They were allocated into two groups. The control group $(n=44)$ received the delta binaural beat while the experimental $(n=45)$ received the beta binaural beat.

As observed in Table 1, in a total number of 89 subjects, they ranged from about 18-23 years old. The average age is 20 years old. Majority were females $(83 \%)$.

An independent t-test further revealed that that there is no significant difference in pretest scores of both groups for memory $(\mathrm{t}=.12, \mathrm{p}=.91)$, reading comprehension $(\mathrm{t}$ $=.20, \mathrm{p}=.84)$ and abstract reasoning $(\mathrm{t}=-.97$, $\mathrm{p}=.33)$.

To test if there is a significant difference between the experimental and control group's pretest and post test scores, a paired t test was done. The paired t-test revealed that there is no significant difference in the control group in terms of memory $(\mathrm{t}=-1.17, \mathrm{p}=.25)$, reading comprehension $(\mathrm{t}=.75, \mathrm{p}=.46)$ and abstract reasoning $(\mathrm{t}=1.37, \mathrm{p}=.18)$. On the other hand, the experimental group showed a significant difference in reading comprehension $(\mathrm{t}$ $=-2.33, \mathrm{p}=.03$ ).

An independent t-test further revealed that there was no significant difference in

Table 1 Demographic profile of fourth year nursing students

\begin{tabular}{lcc}
\hline \multicolumn{1}{c}{ Profile } & F & \% \\
\hline Age* & 1 & \\
18 & 37 & 1.12 \\
19 & 39 & 41.57 \\
20 & 7 & 43.82 \\
21 & 4 & 7.87 \\
22 & 1 & 4.50 \\
23 & & 1.12 \\
Gender & 15 & \\
Male & 74 & 16.85 \\
Female & & 83.15 \\
\hline
\end{tabular}

Table 2 Pretest Scores of Experimental and Control Group

\begin{tabular}{|c|c|c|c|c|c|c|c|c|}
\hline \multirow[t]{2}{*}{ Variable } & \multicolumn{2}{|c|}{ Control } & \multicolumn{2}{|c|}{ Experimental } & \multirow[t]{2}{*}{$\mathbf{t}$} & \multirow[t]{2}{*}{$\mathbf{p}$} & \multicolumn{2}{|c|}{ CI } \\
\hline & $\mathbf{M}$ & SD & $\mathbf{M}$ & SD & & & $\mathbf{L L}$ & UL \\
\hline Memory & 6.27 & 2.20 & 6.33 & 2.71 & 0.12 & 0.91 & -0.98 & 1.10 \\
\hline $\begin{array}{l}\text { Reading } \\
\text { Comprehension }\end{array}$ & 5.95 & 2.01 & 6.04 & 2.24 & 0.20 & 0.84 & -0.81 & 0.99 \\
\hline Abstract Reasoning & 9.18 & 2.04 & 8.73 & 2.30 & -0.97 & 0.33 & -1.36 & 0.47 \\
\hline
\end{tabular}


Johnny J. Yao Jr: Beta Binaural Beats and Its Effect on The Cognition of Nursing Students

Table 3 Pre-test and Post-test Scores of Experimental and Control Group

\begin{tabular}{|c|c|c|c|c|c|c|c|c|}
\hline \multirow[t]{2}{*}{ Variable } & \multicolumn{2}{|c|}{ Pretest } & \multicolumn{2}{|c|}{ Post-test } & \multirow[t]{2}{*}{$\mathbf{t}$} & \multirow[t]{2}{*}{$\mathbf{p}$} & \multicolumn{2}{|c|}{ CI } \\
\hline & $\mathbf{M}$ & SD & $\mathbf{M}$ & SD & & & $\mathbf{L L}$ & $\mathbf{U L}$ \\
\hline \multicolumn{9}{|l|}{ Experimental } \\
\hline Memory & 6.44 & 2.83 & 7.28 & 3.30 & -1.62 & 0.11 & -1.90 & 0.21 \\
\hline $\begin{array}{l}\text { Reading } \\
\text { Comprehension }\end{array}$ & 5.95 & 2.35 & 6.95 & 2.19 & -2.33 & $0.03 *$ & -1.87 & -0.13 \\
\hline Abstract Reasoning & 8.82 & 2.32 & 8.69 & 2.37 & 0.30 & 0.76 & 1.73 & 0.99 \\
\hline \multicolumn{9}{|l|}{ Control } \\
\hline Memory & 6.20 & 1.81 & 6.86 & 3.19 & -1.17 & 0.25 & -1.80 & 0.48 \\
\hline $\begin{array}{l}\text { Reading } \\
\text { Comprehension }\end{array}$ & 6.03 & 2.08 & 5.71 & 1.71 & 0.75 & 0.46 & -0.53 & 1.16 \\
\hline Abstract Reasoning & 9.40 & 2.05 & 8.66 & 2.93 & 1.37 & 0.18 & -0.36 & 1.85 \\
\hline
\end{tabular}

Note: $\mathrm{M}=$ mean, $\mathrm{SD}=$ standard deviation, $\mathrm{CI}=$ confidence interval, $\mathrm{LL}=$ lower limit, $\mathrm{UL}=$ upper limit

$* \mathrm{p}<0.05$

Table 4 Post-test Scores of Experimental and Control Group

\begin{tabular}{|c|c|c|c|c|c|c|c|c|}
\hline \multirow[t]{2}{*}{ Variable } & \multicolumn{2}{|c|}{ Control } & \multicolumn{2}{|c|}{ Experimental } & \multirow[t]{2}{*}{$\mathbf{t}$} & \multirow[t]{2}{*}{$\mathbf{p}$} & \multicolumn{2}{|c|}{ CI } \\
\hline & $\mathbf{M}$ & SD & $\mathbf{M}$ & SD & & & $\mathbf{L L}$ & UL \\
\hline Memory & 7.05 & 3.32 & 7.04 & 3.18 & 0.001 & 0.99 & -1.37 & 0.37 \\
\hline $\begin{array}{l}\text { Reading } \\
\text { Comprehension }\end{array}$ & 6.00 & 1.84 & 7.00 & 2.11 & 2.38 & 0.02 & 0.16 & 1.84 \\
\hline Abstract Reasoning & 8.59 & 2.67 & 8.51 & 2.31 & -0.15 & 0.88 & -1.13 & 0.97 \\
\hline
\end{tabular}

Note: $\mathrm{M}=$ mean, $\mathrm{SD}=$ standard deviation, $\mathrm{Cl}=$ confidence interval, $\mathrm{LL}=$ lower limit, $\mathrm{UL}=$ upper limit

$* \mathrm{p}<0.05$

Table 5 Adverse effects experienced by the research subjects

\begin{tabular}{lccc}
\hline & Experimental & Control & Total \\
\hline Headache & 2 & 4 & 6 \\
Ringing of ears & 2 & 3 & 5 \\
Both & 2 & 2 & 4 \\
None & 39 & 35 & 74 \\
Total & 45 & 44 & 89 \\
\hline
\end{tabular}

post-test scores of both groups for memory $(\mathrm{t}=.001, \mathrm{p}=0.99)$ and abstract reasoning $(\mathrm{t}$ $=-.15, \mathrm{p}=.88$ ). However, there is significant difference in the post test score for reading comprehension $(\mathrm{t}=2.38, \mathrm{p}=.02)$.

As seen in Table 5, a total 15 people experienced adverse effects. Six people experienced headache, five people experienced ringing of the ears, and four people experienced both.

\section{Discussion}

The pre-test scores between scores indicates that both, the experimental and control group, are more or less likely of the same level in terms of cognition specifically in memory, reading comprehension as well as abstract reasoning. This would reflect a successful randomization of subjects between the two groups. Randomization pertains to the random selection of each subject to a group of either 
experimental or control with its primary function to secure comparable groups for equality with respect to extraneous variables. It is considered to be the most effective method of controlling extraneous variables and eliminates selection bias in which the random selection of subjects to either the experimental or control group is not achieved (Polit \& Beck, 2017).

Those in the experimental group had higher scores in reading comprehension compared to the control group. This suggests that the beta binaural beats is effective in reading comprehension. This is in line with the Helmholtz's theory which states that a frequency following response is made by the brain to match the frequency of the stimuli which entrains the brain into a beta brainwave pattern. Beta brainwaves is associated with attention. Moreover, it is said that the higher the attention span, the more likely it is for reading comprehension to increase (Yildiz \& Çetinkaya, 2017). This suggests that the beta binaural beats is effective in reading comprehension. Furthermore, attention would influence information processing of complex information (Wulandari \& Ismail, 2019).

Studies show that an enhanced reading comprehension skill improves reading fluency. It increases the accuracy of word recognition and would allow you to understand structured sentences clearly while skimming and scanning. These studies have also stated that reading comprehension is associated with attention. In line with that, studies have shown that beta binaural beats can increase attention (Garcia-Argibay et al., 2019; Kennel et al., 2010)

However, the paired t-test in the experimental group revealed that there is no significant difference for memory $(\mathrm{t}=1.62, \mathrm{p}$ $=.11)$ and abstract reasoning $(\mathrm{t}=.30, \mathrm{p}=.76)$. This is contradicting to several studies which stated that beta binaural beats is an effective method in facilitating memory. (GarciaArgibay et al., 2019; Huang \& Charyton 2008; Kennerly, 2013). No studies have been found with regards to the effects of beta binaural beats on abstract reasoning.

After the intervention was done, the scores of the experimental group in terms of reading comprehension improved. Improving reading skills will reduce unnecessary reading time and enable a person to read in a more focused and selective manner. The person will also be able to increase their levels of understanding and concentration. Among other studies, an effective result in memory was shown after using beta binaural beats as an intervention (Garcia-Argibay et al., 2019; Huang and Charyton, 2008; Kennerly, 2013). On the other hand, no studies were found about the effects of beta binaural beats on abstract reasoning. Ringing of the ears was a side effect based on experience by the subjects. For the subjects who experienced these effects, they were given the choice whether they would want to continue to participate in the study. All 15 subjects who experienced these effects claimed that they were relieved after resting or sleeping.

There may be some potential limitations to this study. Only the 4th year nursing students were included in the study since there were no enrollees for the lower year levels due to a recent shift in the basic education system during data collection. Therefore, a larger population may increase the possibility of obtaining a significant relationship. The study was conducted in the afternoon wherein the subject was already exhausted due to their morning classes. Lastly, there are unavoidable external noises that may have altered the result of the study.

\section{Conclusion}

Nursing students had improved their reading comprehension while using beta binaural beats. It is effective in reading comprehension, but not in memory and abstract reasoning. Therefore, beta binaural beats may use as a way of boosting cognition specifically reading comprehension.

\section{References}

Conca, L. (2010). Helping students understand what they read. Retrieved January 5, 2020, from https://www.facultyfocus. com/articles/effective-teaching-strategies/ helping-students-understand-what-they-read/ 
Johnny J. Yao Jr: Beta Binaural Beats and Its Effect on The Cognition of Nursing Students

Dy, M., Ferrido, M., Espiritu-Santo, K., \& Ria, S. (2015). Stressors and stress responses of Filipino college students. Asia Life Sciences, 24(2), 737-759.

Ericksen, K. (2017). The importance of critical thinking skills in nursing. Retrieved January 5, 2020, from http://www.rasmussen. edu/degrees/nursing/blog/understandingwhy-nurses-need-critical-thinking-skills/

Garcia-Argibay, M., Santed, M. A., \& Reales, J. M. (2019). Efficacy of binaural auditory beats in cognition, anxiety, and pain perception: A meta-analysis. Psychological research, 83(2), 357-372. https://doi. org/10.1007/s00426-018-1066-8

GetMyUni (n.d). Nonverbal reasoning placements. Retrieved December 23, 2019, from https://www.getmyuni.com/non-verbalreasoning/figure-matrix

Huang, T. L., \& Charyton, C. (2008). A comprehensive review of the psychological effects of brainwave entrainment. Alternative therapies in health and medicine, 14(5), 3850.

Kennel, S., Taylor, A. G., Lyon, D., \& Bourguignon, C. (2010). Pilot feasibility study of binaural auditory beats for reducing symptoms of inattention in children and adolescents with attentiondeficit/hyperactivity disorder. Journal of pediatric nursing, 25(1), 3-11. https://doi. org/10.1016/j.pedn.2008.06.010

Kennerly, R. (2013). An empirical investigation into the effect of beta frequency binaural-beat audio signals on four measures of human memory. Retrieved December 23, 2019 from https://hemi-sync.com/researchpapers/
Lane, J., Kasian, S., Owens, J., \& Marsh, G. (1998). Binaural auditory beats affect vigilance performance \& mood. Physiology \& Behavior, 63(2), 249-252. https://doi. org/10.1016/s0031-9384(97)00436-8

Oster, G. (1973). Auditory beats in the brain. Retrieved December 23, 2019, from http:// www.amadeux.net/sublimen/documenti/

Polit, D. \& Beck, C. (2017). Nursing research: Generating and assessing evidence for nursing practice (10th ed). Wolters Kluwer Health.

Potter, P., Wolf, L., Boxerman, S., Grayson, D., Sledge, J., Dunagan, C., \& Evanoff, B. (2005). An analysis of nurses' cognitive work: A new perspective for understanding medical errors. In K. Henriksen (Eds.) et. al., Advances in patient safety: From research to implementation (Volume 1: Research findings). Agency for Healthcare Research and Quality (US).

Wulandari, T. S. \& Ismail, S. (2019). Exploring nurses' experience of managing attention and mood in post-stroke patients: A qualitative study. Jurnal Keperawatan Padjadjaran, 7 (2), 110-116. https://doi. org/10.24198/jkp.v7i2.1000.

Yauri, I., Nash, R., and Ramsbotham, J. (2019). Improving Student Nurses' ClinicalReasoning Skills: Implementation of a Contextualised, Guided Learning Experience. Jurnal Keperawatan Padjadjaran, 7 (2), 152163, https://doi.org/10.24198/jkp.v7i2.1166

Yildiz, M. \& Çetinkaya, E. (2017). The relationship between good readers' attention, reading fluency and reading comprehension. Universal Journal of Educational Research, 5(3), 366-371. https://doi.org/10.13189/ ujer.2017.050309 